\title{
Reverse logistics: feasibility analysis of the collection and restitution of lubricating oil used or contaminated
}

\author{
Gabriel Cappello Machado ${ }^{1}$, Pedro Pereira Feres ${ }^{2}$, Max Filipe Silva Gonçalves ${ }^{3}$
}

${ }^{1,2,3}$ Universidade Presbiteriana Mackenzie. Rua da Consolação, 930 Consolação, São Paulo-SP.

Email: hwcgligoco@gmail.com, pedropferes@gmail.com, max.goncalves@mackenzie.br

Received: January $07^{\text {th }}, 2019$

Accepted: January $20^{\text {th }}, 2019$

Published: March $31^{\text {th }}, 2019$

Copyright (C2016 by authors and Institute of Technology Galileo of Amazon (ITEGAM).

This work is licensed under the Creative Commons Attribution International

License (CC BY 4.0).

http://creativecommons.org/licenses/by/4.0/

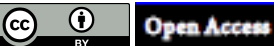

\section{ABSTRACT}

The logistics function is to create and maintain internal and external storage and distribution processes of raw materials and products. Within logistics, we highlight the reverse logistics area, which deals with all operations aimed at recovering and reusing products and materials that have already ended their useful life in the market, thus ensuring their reintegration into the production process, reducing costs and waste. This article aims to make a brief analysis of the current scenario of collection of used and contaminated lubricating oils (UCLO), focusing on the relationship between the low number of collecting stations and the current Brazilian legislation regarding the characterization and requirements to become a collector of UCLO. It is concluded that current Brazilian legislation encourages companies producing and importing finished oils to maintain the current level of collection of used and contaminated oils for convenience.

Keywords: reverse logistics, waste, lubricating oil.

\section{Logística reversa: análise viabilidade da coleta e a restituição de óleo lubrificante usado ou contaminado}

\begin{abstract}
RESUMO
A logística tem como função criar e manter processos de armazenagem e distribuição tanto interna como externa de matérias primas e produtos. Dentro da logística, destaca-se a área de logística reversa, que trata de todas as operações voltadas à recuperação e reutilização de produtos e matérias que já terminaram sua vida útil no mercado, garantindo assim sua reintegração ao processo produtivo, reduzindo custos e resíduos. Este artigo tem como objetivo fazer uma análise sucinta do cenário atual de recolhimento dos óleos lubrificantes usados e contaminados (OLUC), focando na relação entre o baixo número de estações coletoras e a atual legislação brasileira quanto a caracterização e exigências para se tornar um coletor de OLUC. Conclui-se que a atual legislação brasileira incentiva as empresas produtoras e importadoras de óleos acabados a manterem o atual nível de recolhimento de óleos usados e contaminados por comodidade.
\end{abstract}

Palavras-Chave: logística reversa, resíduo, óleo lubrificante.

\section{INTRODUÇÃO}

A prevenção do descarte e a redução de resíduos sólidos têm sido cada vez mais reguladas pelo poder público, o qual vem provendo instrumentos necessários para o avanço do país voltados à redução de problemas ambientais, sociais e econômicos, gerados pelo descarte e manipulação incorreta dos resíduos sólidos.

Os OLUCS (óleo lubrificante usado ou contaminado) em sua maioria são coletados por postos de gasolina e oficinas mecânicas no momento em que é realizado o serviço de troca de óleo usado pelo novo. Este composto é classificado como um resíduo perigoso, sendo inflamável, corrosivo, tóxico e patogênico [1]. Além disso, o descarte de maneira inadequada resulta em problemas ambientais, potencializados pela falta de informação dos riscos e impactos tanto à saúde das pessoas quanto ao meio ambiente.

Desde a criação das máquinas e dos veículos automobilísticos, o óleo lubrificante sempre desempenhou um papel essencial para o bom funcionamento de processos mecânicos. No entanto, esse óleo usado ou contaminado, 
quando não recolhido ou descartado de modo indevido, transforma-se em um problema ambiental, criando-se assim a necessidade do fluxo da logística reversa, desde a identificação do mercado consumidor até o ponto de origem [2].

Foi analisada pelos pesquisadores do presente artigo a cadeia da logística reversa do óleo lubrificante usado ou contaminado, na tentativa de verificar os impactos positivos resultantes do aumento da coleta e reciclagem no âmbito de fatores econômicos, socais e ambientais do Brasil. Após a construção e entendimento do cenário atual, tem-se como objetivo propor uma alternativa dentro da realidade atual para buscar um aumento do percentual de OLUC recolhido para rerefino, focando especialmente nas áreas onde a logística reversa do mesmo é precária.

O óleo lubrificante que é utilizado nos motores dos carros e em máquinas, sofre deterioração devido à perda de propriedades moleculares em função de sua circulação nos processos internos do motor e das máquinas em geral, o que acarreta a necessidade de constante revisão, troca e manutenção do óleo lubrificante.

Tendo em vista a busca do descarte correto, que não gere qualquer poluição ao ambiente, leis ambientais foram criadas pelo governo a partir da década de 90. Além disso, estas leis criaram exigências para a produção, comercialização e refinamento destes produtos, que precisam ser analisados e identificados tanto pela composição quanto sobre a utilização adequada deles, perante aos diversos tipos de veículos tais como carros, ônibus e caminhões [3].

Atualmente 39,74\% do óleo lubrificante usado já é recolhido para rerrefino no Brasil [4], porém grande parte desse número se deve as regiões sudeste e sul do Brasil onde políticas de coleta já estão mais desenvolvidas. O centro-oeste, norte e nordeste ainda estão longe de possuírem um percentual de coleta adequado [5].

Segundo o [6], a nível nacional existem 25 coletores certificados de óleos lubrificantes usados ou contaminados que trabalham através da coleta porta a porta em oficinas e postos de troca de óleo. Após recolhido, este óleo segue para uma rerrefinaria onde $80 \%$ a $85 \%$ é reaproveitado tornando-se óleo básico que é posteriormente misturado a aditivos para se tornar lubrificantes específicos para as mais variadas máquinas.

Somente em 2017 foram produzidos mais de 1 milhão de metros cúbicos de óleo lubrificante no Brasil, que posteriormente se tornará em um OLUC, levando em consideração que atualmente $60 \%$ dos óleos descartados ainda não são reciclados da maneira correta, fica clara a importância do aperfeiçoamento do processo de logística reversa para este produto, pensando-se na necessidade de aumento da porcentagem de sua coleta, reciclagem, refinamento. A relevância disso é fundamentada pelo fato de que quando descartado incorretamente pode poluir grandes quantidades de agua, ar, causar câncer, má formação de fetos entre outros problemas de saúde gravíssimos. Para se dimensionar tamanho prejuízo ambiental causado por este descarte indevido a agua, por exemplo, 1 litro de OLUC pode contaminar até 1 milhão de litros de agua, restringindo a passagem de luz e as trocas de gasosas afetando a vida dos organismos aquáticos.

O trabalho irá se basear em uma metodologia focada na pesquisa e construção do cenário atual de coleta de óleo por regiões do Brasil, identificando quantidade de coletores registrados, maneira e frequência com que é feita a coleta e possíveis outras destinações dos OLUC's que não a correta (rerefino). Após a construção e entendimento do cenário atual, será desenvolvida uma alternativa dentro da realidade atual para buscar um aumento do percentual de OLUC recolhido para re-refino, focando especialmente nas áreas onde a logística reversa do mesmo é precária.

\section{PRINCIPAIS ASPECTOS DA SUSTENTABILIDADE E A LOGÍSTICA REVERSA}

A definição de Logística apresentada por [7] estabelece que a logística engloba "todas as formas de movimento de produtos e informações" dentro do processo da cadeia produtiva ou linha de produção.

Uma das áreas da logística empresarial é a logística reversa, que envolve todas as operações relacionadas à reutilização de produtos e materiais, na busca de uma reintegração destes a processos produtivos sustentáveis, sendo portanto, um instrumento de desenvolvimento econômico e social, visando o reaproveitamento de resíduos industriais para sua reintrodução no ciclo produtivo.

O objetivo da logística reversa é a revalorização de um produto ou material, motivado pela crescente demanda em manutenção de resíduos e também pela redução ao dano ambiental, ao evitar que esse resíduos sejam lançados diretamente na natureza.

O campo de atuação da logística reversa abrange três áreas: econômica, social e ambiental. Economicamente, é feita uma análise para identificar como a logística reversa esta voltada à diminuição dos custos de uma empresa ou órgão público. Já a área ambiental abrange a preocupação e condicionamento dos mecanismos de produção para que estes estejam compatíveis com leis de proteção e preservação ambiental [8]. Por fim, o campo social visa estabelecer condições favoráveis para uma sociedade próspera e desenvolvida além de sustentável e saudável, visando desenvolver métodos para uma melhor qualidade de vida através das atividades da logística reversa.

\section{II.1 PRINCIPAIS ASPECTOS DO DESCARTE INCORRETO DE ÓLEOS LUBRIFICANTES (OLUC'S)}

Além de possuírem diversos componentes danosos ao meio ambiente, como cádmio, chumbo e cromo, os olucs contêm substâncias decorrentes da decomposição de outros metais do motor ou equipamento, como ferro [9].

Esses componentes são altamente tóxicos e nocivos à saúde humana e à natureza e por serem bioacumulativos, essas substâncias não deixam o organismo, causando doenças como câncer, asma, danos á pele e ao sistema respiratório. Outro aspecto que impacta diretamente na saúde humana é em relação ao descarte incorreto feito em esgotos, o que pode levar ao comprometimento do funcionamento de estações de tratamento de água utilizada por milhares de pessoas [10].

Além disso, os lubrificantes mal descartados poluem o ar e as águas, podendo afetar também todo um ecossistema, destruindo fauna, flora e lençóis freáticos, causando problemas na fotossíntese das plantas e impactando a cadeia alimentar. É estimado que apenas um litro de óleo não descartado 
corretamente basta para contaminar 1 milhão de litros de água [9].

Segundo [9], não obstante esse panorama, o setor de lubrificantes é responsável por uma quantia considerável em relação ao gasto de energia e recursos, tanto naturais, quanto financeiros, gerando um número elevado de resíduos gasosos, líquidos e sólídos tóxicos que impactam diretamente no meio ambiente e na vida da população.

Fica claro, portanto, que a logística reversa de lubrificantes utilizados na indústria tem papel essencial para a prevenção de danos à saúde humana e ao meio ambiente.

\section{II.2 LEGISLAÇÃO AMBIENTAL DA LOGÍSTICA REVERSA DOS OLUC'S}

O óleo lubrificante, ao ser utilizado sofre deterioração de seus componentes, perdendo suas propriedades químicas, tornando-se um resíduo tóxico perigoso. Devido a este fato, foram criadas leis para o controle do recolhimento e coleta deste óleo, além de regular uma destinação final para o produto, para assim diminuir o descarte incorreto e evitar maiores danos ambientais. Segundo a Resolução CONAMA 362/2005 que trata da coleta, recolhimento, e destinação final de óleo lubrificante usado ou contaminado [3]:

"Art. 1": Todo óleo lubrificante usado ou contaminado deverá ser recolhido, coletado e ter destinação final, de modo que não afete negativamente o meio ambiente e propicie a máxima recuperação dos constituintes nele contidos, na forma prevista nesta Resolução."

Foi determinada na Resolução CONAMA 362/2005 a responsabilidade ao produtor e importador de realizar o recolhimento, coleta e destinação final do óleo utilizado, criando assim a necessidade de os mesmos realizarem toda a logística reversa deste produto, garantindo a destinação final do óleo lubrificante usado ou contaminado. Além disso, a identificação da quantidade de óleo a ser recolhida pelos produtores e importadores está diretamente relacionada com a proporção da quantidade de óleo distribuída por eles no mercado [3] .

Segundo a Resolução CONAMA n 362/2005 partir da coleta do óleo usado, uma técnica, chamada de rerrefino, é utilizada para a reintegração do óleo contaminado por meio da reciclagem e da recuperação de suas características químicas primarias. Porém nem sempre este processo é realizado de modo correto, já que diversos estabelecimentos em todo o território nacional realizam a coleta deste óleo para outros fins divergindo do que é regulado pela legislação atual [3].

"A prática tecnicamente recomendada para evitar a contaminação ambiental — estabelecida pela Resolução Conama $n^{o}$ 362/2005 - é o envio do óleo lubrificante usado para reciclagem e recuperação de seus componentes úteis por meio de um processo industrial conhecido como rerrefino."

Devido ao fato do petróleo brasileiro ser considerado pobre em óleo básico em consequência das suas características químicas e este insumo ainda ser necessário para a fabricação de óleo lubrificante, o processo de rerrefino possui grande relevância para a politica estratégica econômica do país, pois este processo realiza a recuperação das partículas nobres presentes no óleo lubrificante. Isso diminui tanto a necessidade de os fabricantes realizarem a importação deste petróleo leve, quanto a produção de novas quantidades deste material que demanda muita energia [3].

Para o controle e aumento de quantidade de óleo devidamente reciclado, o governo criou um sistema de metas, cabendo aos Ministérios de Meio Ambiente e de Minas e Energia atribuir acompanhar o cumprimento das metas da coleta de óleo lubrificante usado e contaminado pelo produtor e importador.

"I - análise do mercado de óleos lubrificantes acabados, na qual serão considerados os dados dos últimos três anos;

II - tendência da frota nacional quer seja rodoviária, ferroviária, naval ou aérea;

- tendência do parque máquinas industriais consumidoras de óleo, inclusive agroindustriais;

IV - capacidade instalada de rerrefino;

V - avaliação do sistema de recolhimento e destinação de óleo lubrificante usado ou contaminado;

VI - novas destinações do óleo lubrificante usado ou contaminado, devidamente autorizadas;

VII - critérios regionais; e

VIII - as quantidades de óleo usado ou contaminado efetivamente coletadas".

Tabela1: Metas estabelecidas pelos Ministérios de Meio Ambiente e de Minas e Energia.

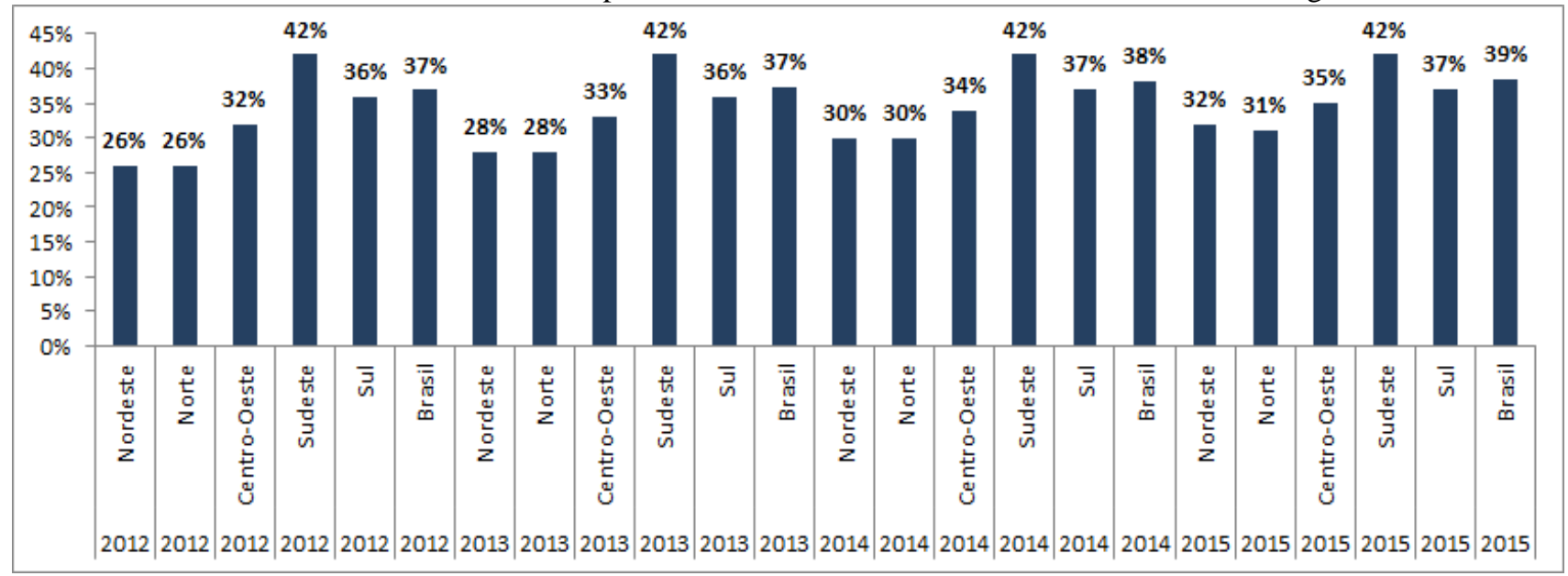

Fonte: Adaptado [4] 
Machado, Feres and Gonçalves, ITEGAM-JETIA. Vol. 05, № 17, pp 62-67. March, 2019.

Tabela2: Cumprimento de Metas estabelecidas pelos Ministérios de Meio Ambiente e de Minas e Energia.

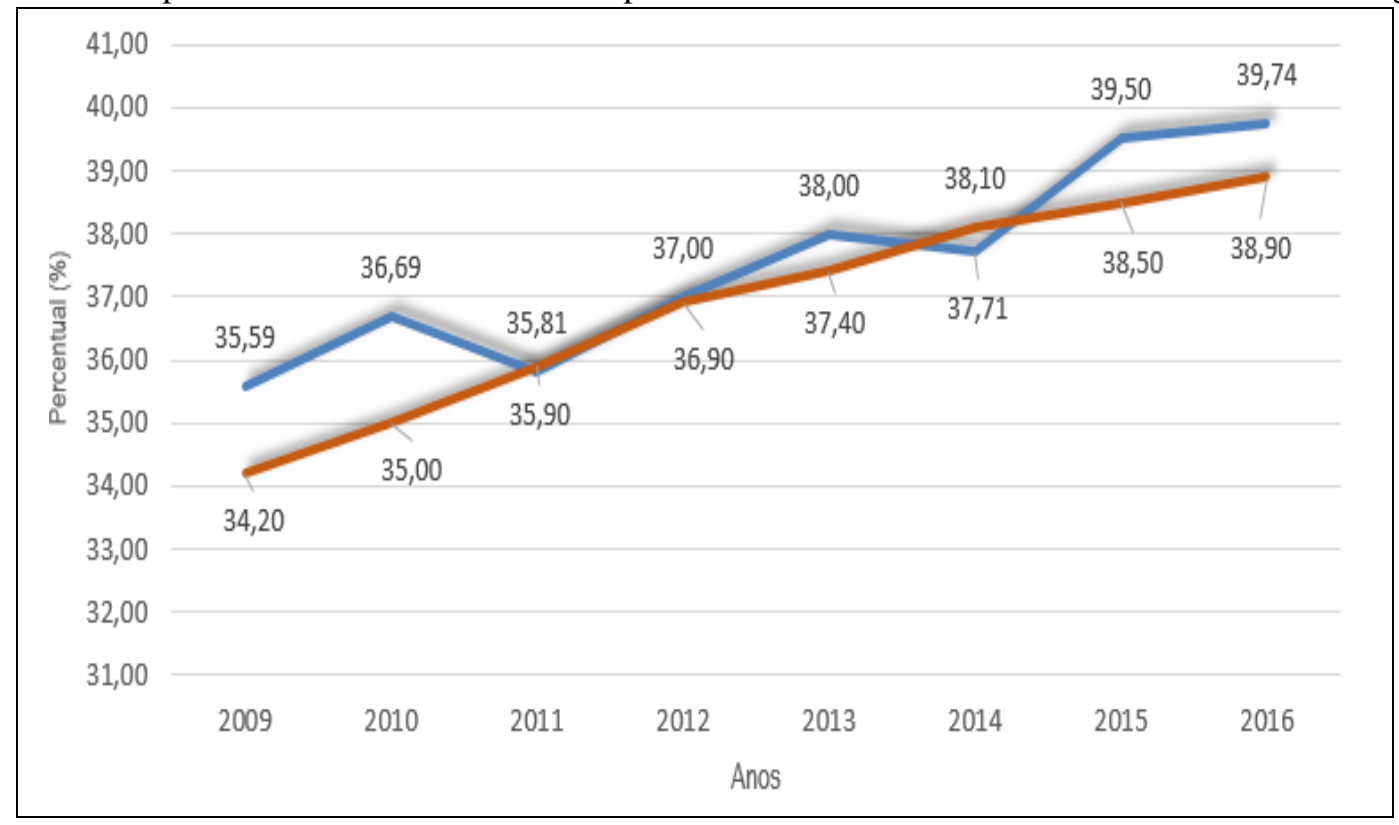

Fonte: [4].

\section{II.3 DISTRIBUIÇÃO TERRITORIAL DE ESTAÇÕES COLETORES E DE RERREFINO DO OLUC}

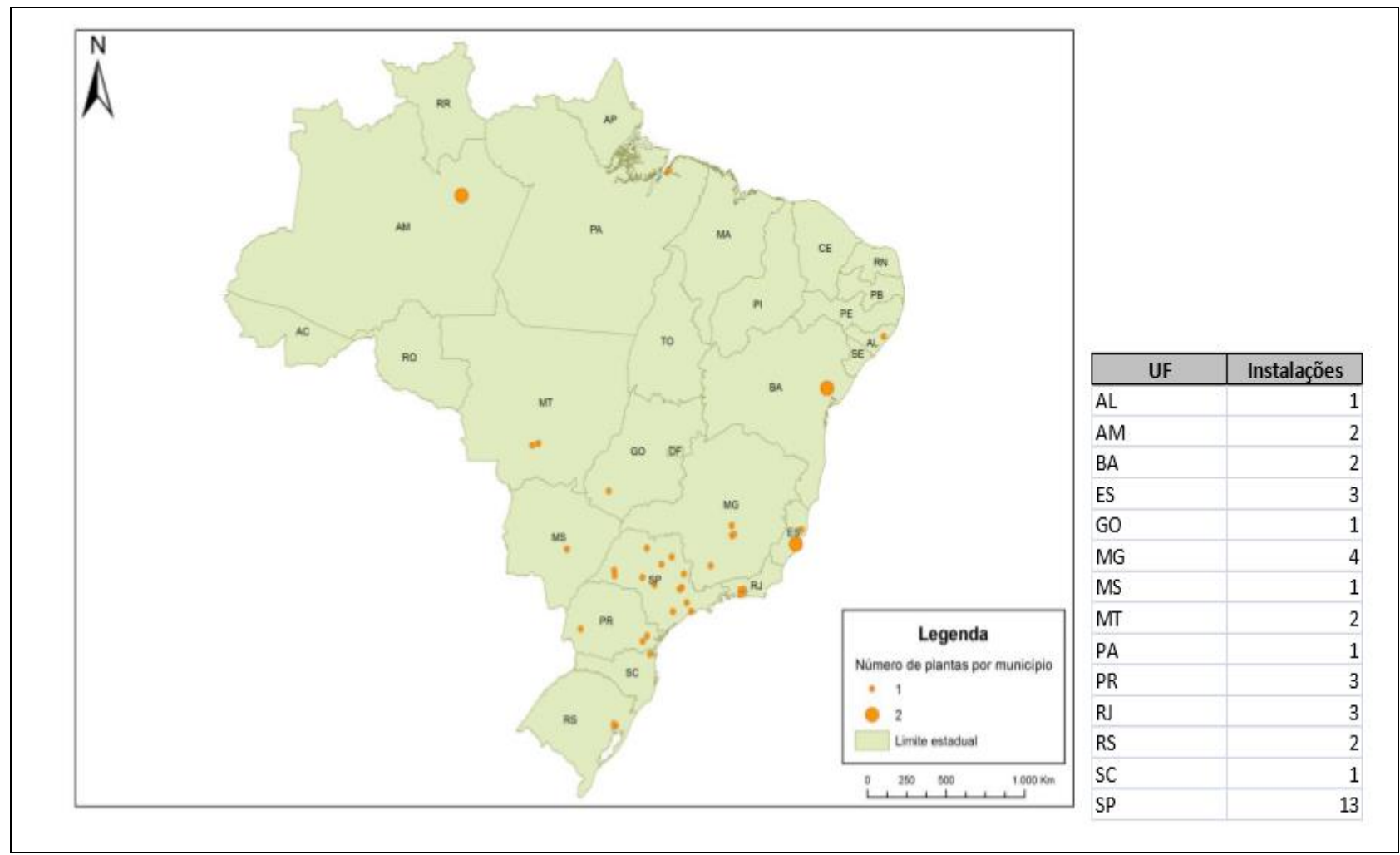

Figura 1: Estações de coleta de OLUC's no Brasil.

Fonte: [4].

Na figura 1, onde é indicado a localização das estações de coletas de OLUC no Brasil, pode se notar que número de coletores registrados é extremamente baixo para um país como o Brasil e mais da metade dos coletores estão concentrados apenas no estado de São Paulo. Quando comparado o número de coletores ao número de produtores e importadores de óleo acabado, fica claro como existe um déficit na logística reversa dos OLUC's. Enquanto que há 302 produtores e importadores de óleos acabados, existem apenas 27 estações de coleta devidamente registradas na Agencia Nacional do Petróleo, Gás Natural e Biocombustíveis.

Na grande maioria dos estados, uma mesma estação de coleta atende a diversos municípios, a figura 2 mostra o número de municípios por estado que possuem ou não coleta. 


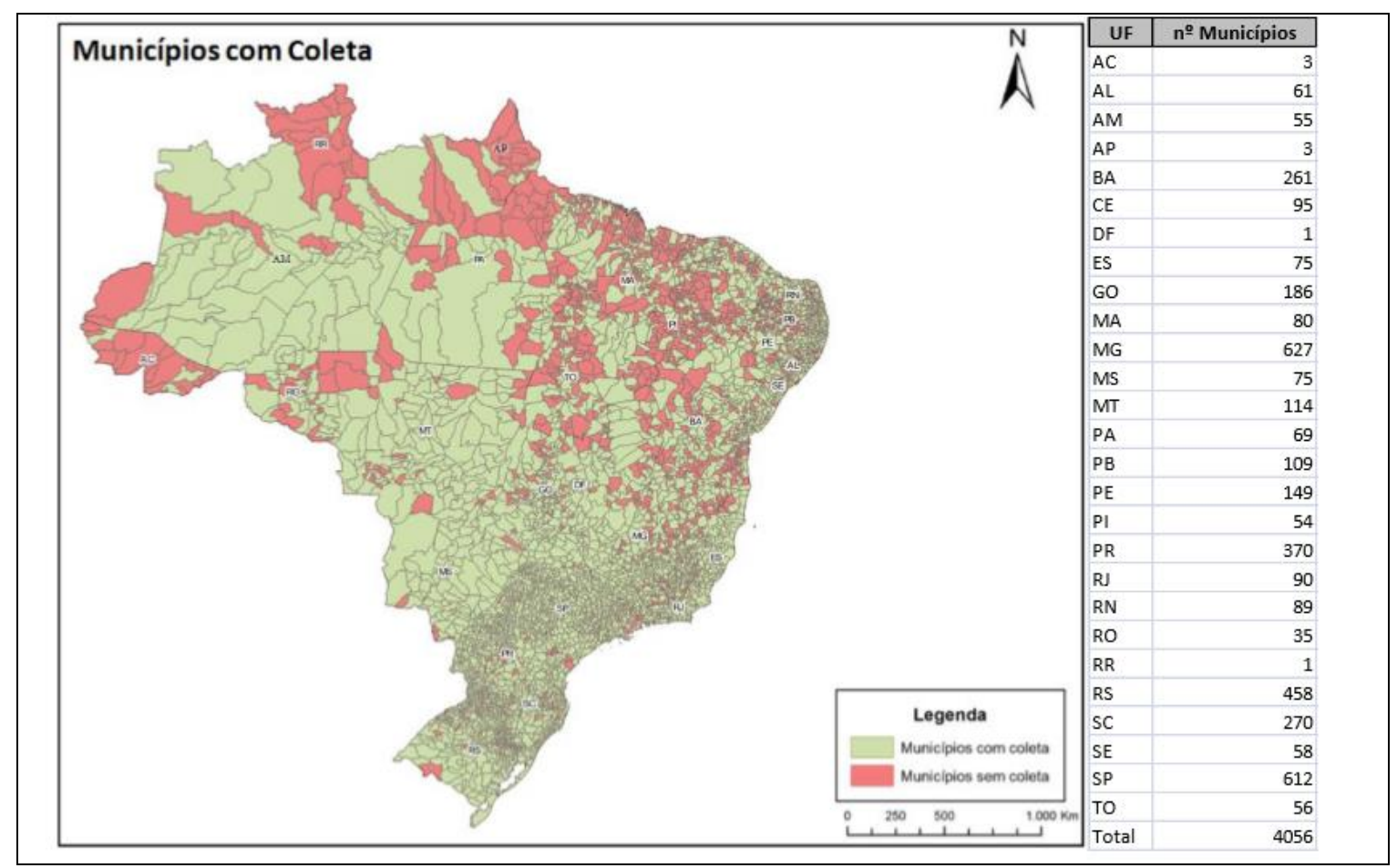

Figura 2: Municípios com coleta no Brasil.

Fonte:[4].

A figura $1 \mathrm{em}$ conjunto com a figura 2 indicam que existe uma relação entre o número de estações coletoras no estado e o número de municípios atendidos pela coleta. Além do número de estações de coleta, a qualidade das estradas e facilidade de locomoção entre um município e outro afetam diretamente o nível de atendimento destas estações, sendo o estado do Amazonas o mais afetado por essas características visto que muitas de suas estradas não são asfaltadas e atravessam grandes partes da floresta amazônica.

Para se tornar um coletor de OLUC's, a agencia nacional do Petróleo, Gás Natural e Biocombustíveis exige que seja realizado um cadastro onde devem ser entregues as seguintes documentações [4]:

- Habilitação e autorização para o exercício da atividade: POI ${ }^{\circ} 27$

- Recadastramento: Procedimento $\mathrm{n}^{\circ} 09$ do Anexo IV da Resolução ANP n 42/2011 (fls. 53-55)

- $\quad$ Autorização de construção (AC): Procedimento $n^{\circ} 09$ do Anexo I da Resolução ANP n 42/2011 (fls. 19-21)

- Requalificação de instalações: Procedimento $n^{\circ} 09$ do Anexo IV da Resolução ANP n 42/2011 (fls. 53-55)

- Autorização de operação (AO): Procedimento $\mathrm{n}^{\circ} 09$ do Anexo II da Resolução ANP n 42/2011 (fls. 3031)

- Resolução ANP no 20/2009 - estabelece os requisitos necessários à autorização para o exercício da atividade de coleta de óleo lubrificante usado ou contaminado e a sua regulação. Revoga as portarias ANP $n^{\circ} 125$ e $n^{\circ}$ 127 de 1999.

Além do requerido para cadastro o interessado em se tornar um coletor de OLUC deve cumprir uma série de premissas para comprovar sua qualificação jurídica e regularidade fiscal, tornando o processo extremamente burocrático, fato que pode ser uma das razões para o baixo número de estações de coletas existentes no Brasil. Deve se notar também que segundo o artigo 7 da resolução $\mathrm{N}^{\circ} 362$, de 23 de junho de 2005 as seguintes responsabilidades com relação a coleta de OLUC são atribuídas aos importadores e produtores de óleos acabados:

“Art. 7 o Os produtores e importadores são obrigados a coletar todo óleo disponível ou garantir o custeio de toda a coleta de óleo lubrificante usado ou contaminado efetivamente realizada, na proporção do óleo que colocarem no mercado conforme metas progressivas intermediárias e finais a serem estabelecidas pelos Ministérios de Meio Ambiente e de Minas e Energia em ato normativo conjunto, mesmo que superado o percentual mínimo fixado."

Portanto muitas das empresas coletoras são na realidade divisões das próprias produtoras e importadoras de óleos lubrificantes acabados, e mesmo quando não possuem vínculo com os produtores e importadores ainda sim possuem suas operações custeadas por eles. Como existe um alto custo ligado a logística reversa dos OLUC e, invariavelmente, as produtoras e importadoras devem arcar com o mesmo, torna-se pouco rentável o interesse em aumentar o número de estações de coleta através da contratação de mais empresas terceirizadas, sendo mais cômodo manter uma operação centralizada e receber os valores provenientes da venda/rerrefino do óleo lubrificante usado ou contaminado.

A centralização das estações de coleta acaba se mostrando prejudicial ao processo de logística reversa como um todo, porém sendo a opção de menor custo para as empresas, acaba sendo o modelo mais adotado. Uma das alternativas encontrada pelos pesquisadores deste artigo para extinguir a prática de centralização das estações de coleta foi a subdivisão da meta criada pelo Ministério do Meio Ambiente em subcategorias que englobam não só quantidade de óleo coletado, como também abrangência da coleta em cada estado e número de municípios que não receberam coleta. 


\section{CONCLUSÃO}

A legislação brasileira referente a destinação de OLUC's é de extrema importância para garantir a diminuição do descarte impróprio deste resíduo extremamente perigoso ao meio ambiente e ser humano, porém nota-se que muitas vezes devido sua complexidade e outros fatores externos, o seu efeito acaba se tornando o contrário do desejado. É inegável que o Brasil aumentou significativamente a coleta de óleos usados e contaminados, porém ainda há muito a melhorar, especialmente nos locais mais remotos onde devido à falta de informação e de opções, o uso de OLUC's de maneiras nocivas ainda é muito comum. A logística reversa deve ter um papel fundamental para transpor os desafios ainda existentes no Brasil quanto ao descarte correto desse tipo de resíduo, podendo ser usada em futuras revisões da legislação para criar resoluções mais eficientes e simples. Além disso, pode-se notar uma contradição em relação à legislação atual e o plano de meta do país, dado que no Art. $1^{\circ}$ da Resolução CONAMA 362/2005 está explicito que todo óleo contaminado deve ser recolhido, e recuperado, ao mesmo tempo que o plano de meta estipulado e fiscalizado pelos Ministérios de Meio Ambiente e de Minas e Energia propõem metas de coleta inferiores a 50\%, reduzindo o incentivo a coleta .

\section{REFERÊNCIAS}

[1] ABNT - Associação Brasileira de Normas Técnicas. NBR 10.004. Resíduos Sólidos - classificação. Rio de Janeiro, 2004.

[2] Canchumani, Giancarlo Alfonso Lovón. Óleos Lubrificantes Usados: um estudo de caso de avaliação de ciclo de vida do sistema de rerrefino no Brasil." COPPE/UFRJ. Rio de Janeiro (2013).

[3] Conselho Nacional do Meio Ambiente (2005), Resolução 362/2005, Regulamentação da Coleta, Transporte, Armazenamento e Destinação Adequada dos óleos lubrificantes usados e contaminados, disponível em: http:// www.mma.gov.br/port/conama/res/res05/res36205.xml (Acesso em 20 de Outubro de 2017).

[4] ANP - Agencia Nacional do Petróleo, Gás Natural e Biocombustíveis. Disponível em: http://www.anp.gov.br/?id=1086. Acesso em: 20 de outubro de 2017.

[5] Brasil. Ministério do Meio Ambiente. Portaria Interministerial MME/MMA n ${ }^{\circ}$ 59, de 17 de fevereiro de 2012. Estabelece os percentuais mínimos de coleta de óleos lubrificantes usados ou contaminados, para o período de 2012 a 2015.

[6] Brasil. Ministério do Meio Ambiente. Relatório: Coleta de óleo lubrificante usado ou contaminado - dados de 2013. Relatório para o Conselho Nacional do Meio Ambiente (CONAMA), conforme exigência do Artigo $9^{\circ}$ da Resolução CONAMA no 362/2005 que trata de Óleos Lubrificantes Usados e/ou Contaminados (OLUC).
[7] Rosa, Heron Flores da. (2008). Gestão da informação em mapeamento logístico de correspondências: um estudo de caso nos Correios do Rio Grande do Sul.

[8] Gomes, P. L; Oliveira, V. B. P; Nascimento, E. A. Aspectos e impactos no descarte de óleos lubrificantes: o caso das oficinas. In: IV Congresso Nacional de Excelência em Gestão ,4., Niterói, RJ, 2008. 15 p.

[9] Sohn , H., (Coord.) (2007), Guia Básico: Gerenciamento de Óleos Lubrificantes Usados ou Contaminados, Senai, São Paulo, SP.

[10] Para Reciclagem, Compromisso Empresarial. CEMPRE.(2013), Ficha técnica. PNEUS. Available in: <http://www. cempre. org. br, 2013>. Acesso em 20 de outubro de 2017. 